\title{
Clinching of inductively heated aluminum die casting
}

\author{
Sinan Yarcu ${ }^{1} \cdot$ Bernd-Arno Behrens ${ }^{1} \cdot$ Sven Huebner ${ }^{1} \cdot$ Torsten Schuchardt $^{2} \cdot$ Klaus Dilger $^{2} \cdot$ Thomas Paul Meichsner $^{3}$
}

Received: 18 November 2021 / Accepted: 4 February 2022 / Published online: 2 March 2022

(c) The Author(s) 2022

\begin{abstract}
The aim of the investigations described in this article is to improve the clinching of aluminum die casting. The focus is on clinching an aluminum die casting alloy by local heat treatment and hence to join them in a process-safe manner. For this purpose, a heating strategy is used to warm up the die casting alloys to reduce temporarily and reversibly the elongation and the yield strength in the material. In preliminary investigations, three different heating strategies (heating plate, resistance heating and inductive heating) have been investigated. Induction heating has been selected as the most suitable method due to the short heating time and the production of crack-free clinch points. In this paper, two clinching tool systems (one with a flexible die, one with a rigid die) were used. For these tools, two inductors with different diameter were manufactured. The effects of each inductor and clinching tool on an aluminum die casting alloy, such as heating time and crack behavior, were investigated. Surface images of the clinch points in regard to the heat treatment temperature were analyzed. Furthermore, the characteristic parameters of the joints such as interlock, bottom thickness and neck thickness were examined. In addition, the strength of the joined parts was investigated by head tension tests. The results of the developed method showed that it is possible to produce crack-free clinching joints below $6 \mathrm{~s}$. Furthermore, the local heating led to an increasing interlock resulting in a $26 \%$ increase of the head tensile strength.
\end{abstract}

Keywords Joint $\cdot$ Clinching $\cdot$ Die casting $\cdot$ Heated clinching $\cdot$ Tempered clinching

\section{Introduction}

In the automotive industry, the multi-material body (MMB) is a trend among manufacturers. The reason for this is that in this design, the choice of materials depends on the load types [1]. In this way, materials with a lower density can be used for less stressed zones in order to reduce the overall weight of the vehicle. However, the aspects of lightweight design, cost (quantities) and performance requirement (stiffness) are contrary to each other when combining various materials [2]. During the design process, mechanical properties and thermal expansion coefficients of the materials must be considered, as these place high demands on joining

Sinan Yarcu

s.yarcu@ifum.uni-hannover.de

1 Institute of Forming Technology and Machines, Leibniz Universität Hannover, 30823 Garbsen, Germany

2 Institute of Joining and Welding, Technische Universität Braunschweig, 38106 Braunschweig, Germany

3 Gusswerke Saarbrücken GmbH, 66130 Saarbrücken, Germany techniques. In order to exploit the combined advantages of all the materials used or the manufacturing processes in large-scale production, new developments must support economical lightweight body construction.

Figure 1 illustrates a mixed design with a high aluminium content using the example of an Audi e-tron GT. With the aid of a load-oriented material combination, a high weight saving was achieved compared with a steel body.

Conventional joining methods reach their limits in the case of the multi-material body. For example, spot welding, which is commonly used for body construction, is less suitable for joining the material combination of aluminum and steel, due to the different thermal properties. In this case, other joining technologies, such as clinching, must be considered. This process has been shown to be suitable in advance.

Aluminum die casting alloys are very brittle in their naturally hard state and hence are only suitable for clinching to a limited extent. Previous studies have shown that cracking occurs on the joining surface using a clinching process [4].

Zhao et al. [5] investigated self-pierce riveting for different aluminum die casting alloys (A380, W3, A6061) 
Aluminium Die Cast

Aluminium Profile

Aluminium She et

Hot Formed Steel

Cold Formed Steel

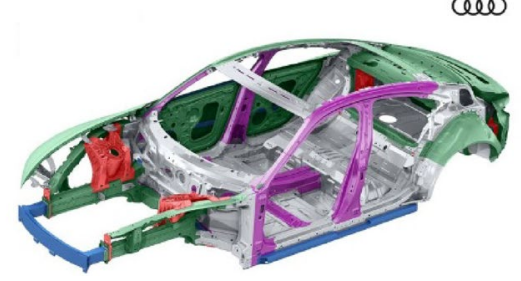

Fig. 1 Aluminum-intensive mixed construction using the Audi e-tron GT Coupé as an example [3]

and focusing on the cause of cracking in these alloys during joining. His explanation for the cracking was the silicon content of the alloy, which causes the elongation at fracture to decrease. However, silicon is important for the casting behavior of the aluminum alloy. The addition of strontium or a heat treatment can improve the elongation at fracture, as this prevents silicon from agglomerating in the material. In the further progress of its study, the aluminum die casting material W3 was heat-treated to temperatures of $200-400{ }^{\circ} \mathrm{C}$. The die casting alloy were joined with a steel sheet material (DP800) and the joint were examined for their crack behavior. The results showed that, although the cracks decrease with increasing heat treatment temperature, the joint strengths also decrease [5]. In further investigations, Zhao [6] found that deeper dies generate larger cracks because the die casting material is exposed to greater deformation.

For example, the company Böllhoff [7] has developed a ring groove die to join brittle materials with aluminum castings in the as-cast state by reducing the additional volume inside the die.

Studies were conducted by Jäckel et al. [8] in the area of self-pierce riveting processes for aluminum die casting. Although the crack formations could be avoided by an optimized tool geometry, the interlocking was reduced [8].

Investigations in the context of friction stir riveting for aluminum die casting was carried out by Hovanski et al. [9]. Since die casting has high brittleness, this is an obstacle for joint quality. As a result, it tends to be more susceptible to fracture and thus more sensitive to bending [9].

Ang [10] provided an overview of semi-hollow stamped riveting with a focus on joint failure, corrosion issues and optimization techniques. In his overview, he noted that there is a high potential for cracking during joining, especially in brittle materials such as magnesium and aluminum die casting [10]. While it is already known from various studies that the cracks in magnesium die casting can be avoided by preheating [11], this approach has not yet been researched for aluminum die casting.

In a previous study, three different heating methods (heating plate, resistance and inductive heating) have been examined in order to obtain crack-free clinch joints [12].
To reduce the brittleness of the aluminum die casting alloy, an annealing step was integrated into the clinching process. The results showed, that the inductive heating method was the most suitable to obtain crack free clinching points in a fast manner. Therefore, this heating method was selected for further investigations, which are presented in this paper. In order to classify the influence of the heating methods on the joinability by means of clinching, the heating time, the surface area and the geometric dimensions of the clinching point as well as the bond strength of the joints were examined.

\section{Experimental setup and materials}

The experiments were carried out on the clinching press DFG-500/150 of the company Eckold and CEB 008 of the company TOX. The tooling system used on the Eckold press is a two-part die with a step punch from the company BTM. The die consists of two blades, which are held together in their initial position by a steel spring. Due to the blade geometry, there is a gap between the blades, which ensures that the blades are pressed apart during clinching. The die was positioned so that its blades were vertical oriented to the press. The step punch used has a diameter of $5.5 \mathrm{~mm}$ and $6.4 \mathrm{~mm}$. Its geometry ensures that sufficient material is pressed into the clinch point and that the neck thickness does not thin out. The tooling system on the TOX press is a rigid die with a cone punch (Fig. 2).

The induction heating process proved to be the most suitable due to its short heating time. Therefore, this heating method was improved for use in series production. In this context, it is especially important to consider the criterion of the heating time as a boundary condition. Furthermore, the place for mounting must be chosen according to practical dimensions. That means a miniaturization of the inductor is necessary.

Based on the inductor used in [12], a miniaturized inductor was developed that meets the requirements for seriesproduction operation. The ring thickness of the inductor was halved. In addition, it was not possible to build one inductor for both clinching presses, since each press has its own special mounting possibilities. Thus, two separate ring inductors were developed, which are adapted to the respective clinching presses and their tools. Figure 3 shows the production drawing of the ring inductors for the Eckold and the TOX press. The difference to the ring inductor for the TOX press is the diameter of the respective ring. The ring inductor for the Eckold press has an inner and outer diameter of $36 \mathrm{~mm}$ and $46 \mathrm{~mm}$, while the TOX press has smaller diameters of $23 \mathrm{~mm}$ and $33 \mathrm{~mm}$. Furthermore, both inductors have a different curvature. This is directed to the right for the Eckold variant and to the left for the TOX variant. Glass silk tape 

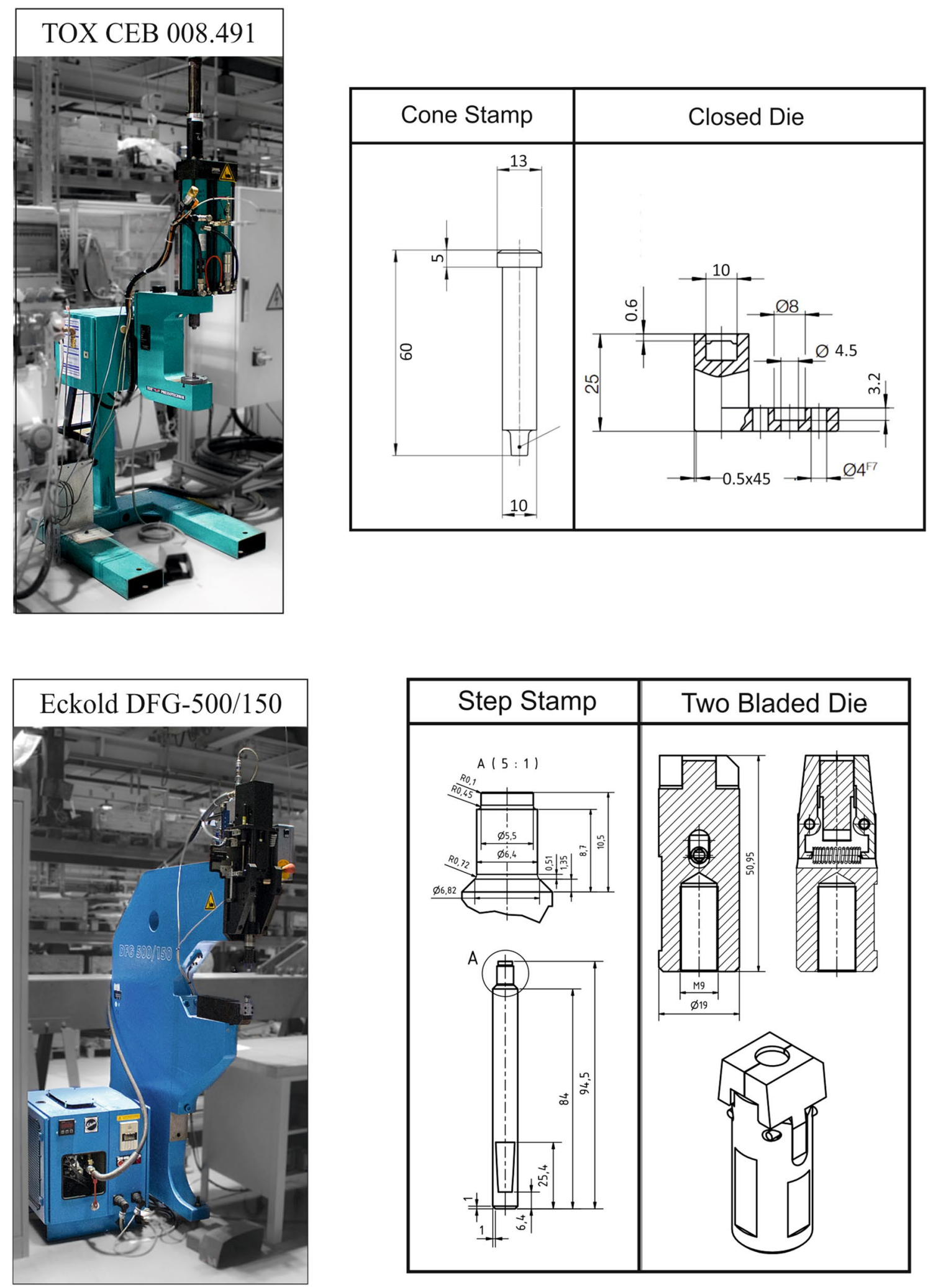

Fig. 2 Clinching press of the company Eckold (down) and the company TOX (up); the used clinching tool system of the company BTM (down) and the company TOX (up) 


\section{Inductor for the Eckold Clinching Press}

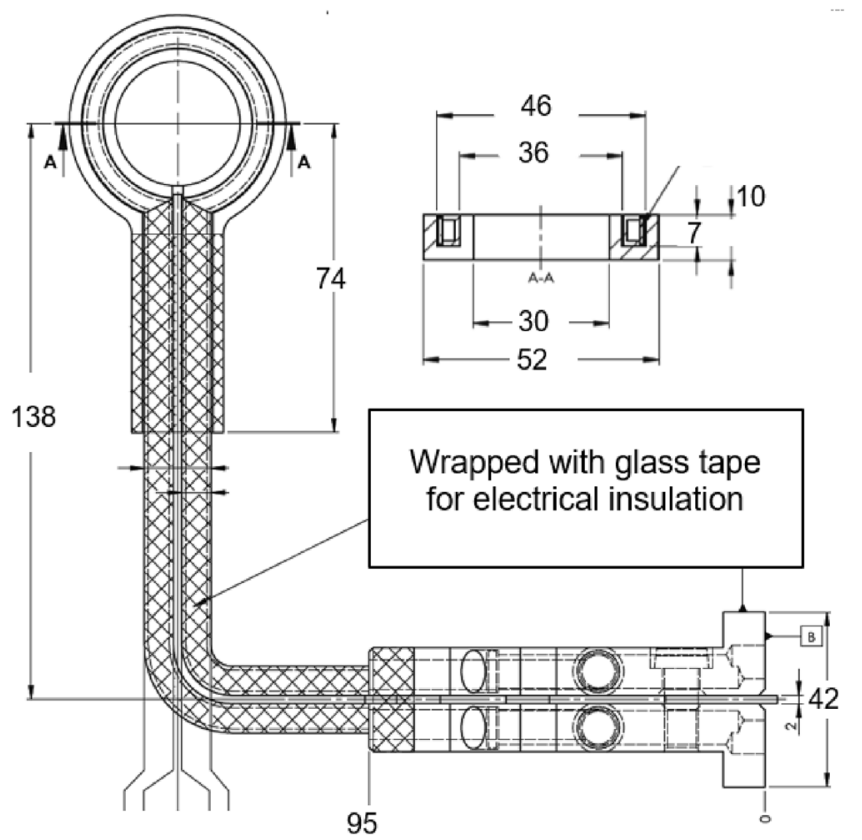

\section{Inductor for the TOX Clinching Press}

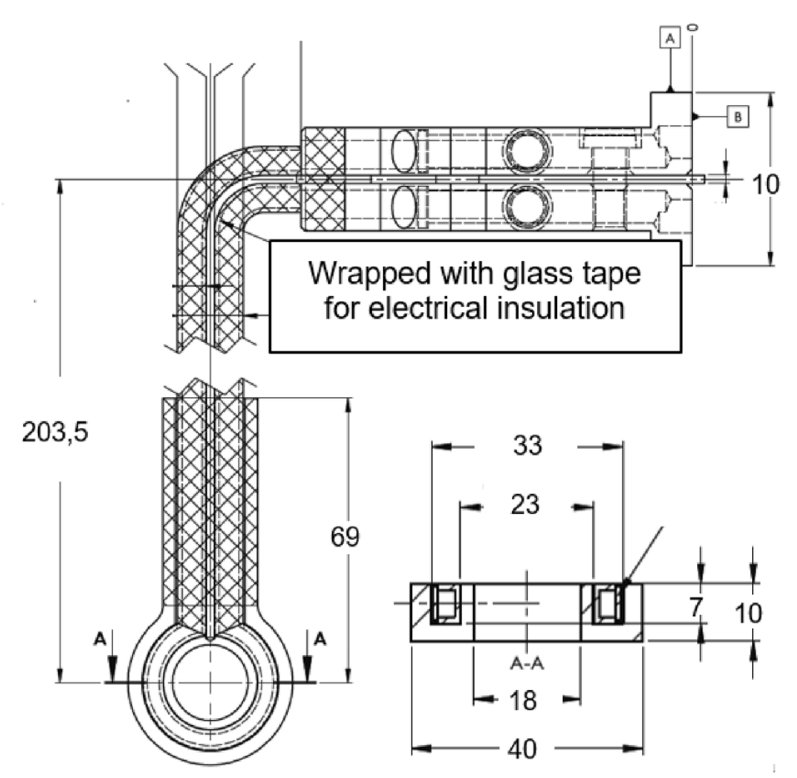

Fig. 3 Production drawing of the miniaturized ring inductor for the Eckold clinching press (left) and for the TOX clinching press (right)

was wound into the leads for electrical insulation. As shown in Fig. 3, the ferrite shielding extends $74 \mathrm{~mm}$ deep into the leads to protect objects below from the magnetic radiation.

The inductors were mounted on the presses using ITEM profiles. The existing drills were used for fastening to the presses. Figure 4 shows the presses with successfully integrated inductors. The areas of the inductor where no glass silk tape could be used for insulation were encased accordingly with a specially manufactured plastic insulation. The water cooling is attached to the generator, which provides the inductor cooling.

The miniaturized ring inductors were first used to experimentally measure the time-temperature curves in the die casting material in order to determine the suitable manipulated variable (generator power) for further investigations. The generator used is MFG 18 from the company Eldec. It has a maximum power of $18 \mathrm{~kW}$ at a maximum frequency of $40 \mathrm{kHz}$ and an active water cooling. The generator power set here is not to be equated with the real power consumption and serves as a control value. The generator regulates the inductor voltage, whereby a higher inductor voltage causes a higher voltage in the workpiece, which in combination with the induced current determines the converted power in the workpiece. The higher the generator power, the more power arrives at the joint. It should also be mentioned that the induced power depends on other factors, such as the air gap between the inductor and the material, as well as geometric conditions with regard to the inductor.
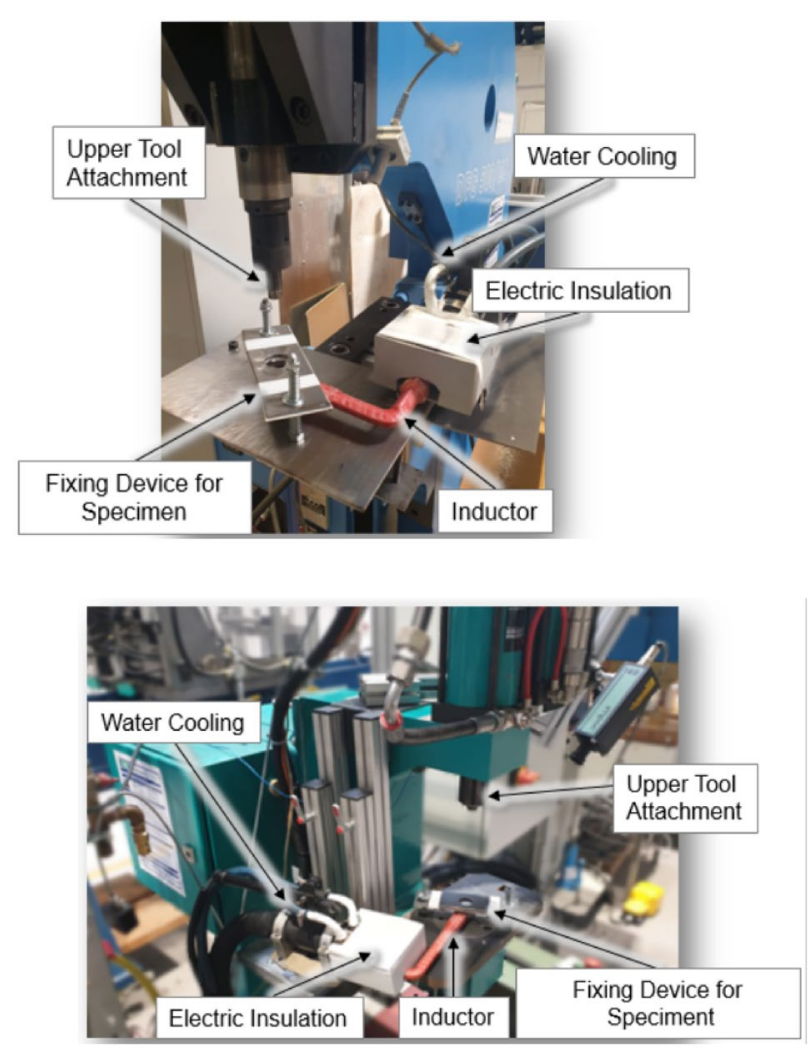

Fig. 4 Setup of the inductive heating concept suitable for series production for the Eckold clinching press (up) and TOX clinching press (down) 
Here, the manipulated variable on the generator was increased stepwise in $10 \%(4 \mathrm{kHz})$ increments starting at $50 \%(20 \mathrm{kHz})$. It is known from the previous induction heating tests that crack-free clinch points can be achieved in die casting beginning with a temperature of $250{ }^{\circ} \mathrm{C}$ [12]. In that case, a different inductor with a larger ring thickness $(10 \mathrm{~mm})$, a wider inner diameter $(40 \mathrm{~mm})$ and a different ferrite shield was used. Therefore, the results from the previous study cannot be applied to this research. Due to the miniaturization of the inductors, which lead to a more concentrated magnetic field for workpiece and clinching tool, lower temperature need to be considered. Because of this, new prior examination was conducted in which the reference temperature was determined at $220^{\circ} \mathrm{C}$. A pyrometer for regulating the temperature was not considered in these tests, since the primary objective was to determine the minimum time window required for temperature-controlled clinching. Temperature regulation would result in a slower warm-up time because it would throttle the generator's output before the actual reference temperature is reached. Therefore, a time-regulated approach was applied, in which the time at the desired temperature is determined by means of time-temperature curves.

\subsection{Investigated materials}

The clinching of aluminum die casting is the focus of this investigation. Therefore, an aluminum die casting alloy EN AC-AlSi9Mn (3 mm) in its as casted condition F is used in the scope of this research. Because the clinching of brittle aluminum die casting is associated with cracks on the surface, this material is placed on the die side so that it is heated directly by means of the inductor. As the punch sided material, the aluminum sheet EN AW-5182 (1.5 mm) was applied.

As part of the material characterization, the die-cast components were analyzed. The strength values such as tensile strength, yield strength and elongation were determined. The tensile specimens correspond to specimen shape $\mathrm{E}$ from the DIN 50125 standard, with removal from the casting close to the ingate, center and venting as shown in Fig. 5 left.

In addition, the fracture surfaces were analyzed in isolated cases and the porosity in the component was determined by means of computer tomography. From the samples, mean values and standard deviation are obtained for the alloy and the sample position. The diagrams in Fig. 5 on the right show the values averaged over the casting component for tensile stress, yield strength (Fig. 5 top right) and elongation at fracture (Fig. 5 bottom right). The determined strength values, especially those for tensile strength and elongation at break, show significantly lower values compared to those from the literature, regardless of the specimen position. The determined proof stresses are in line with the values from the literature. The strong scatter among the specimens is also noticeable. This behavior is caused by statistically distributed cold shut in the material. Such a cold shut can be seen in the scanning electron micrograph in Fig. 6 on the left. The tensile strength for this sample is $175 \mathrm{MPa}$ and the elongation at break is $1.9 \%$. Both values are very low for this alloy. The image shows a dark matte area in the center of the
Fig. 5 Casting part with the sample positions (left) and measured mechanical properties

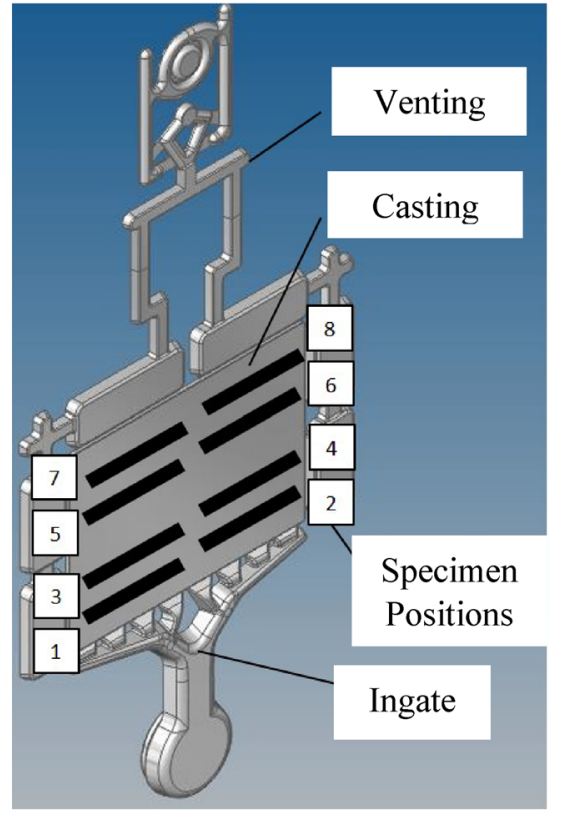

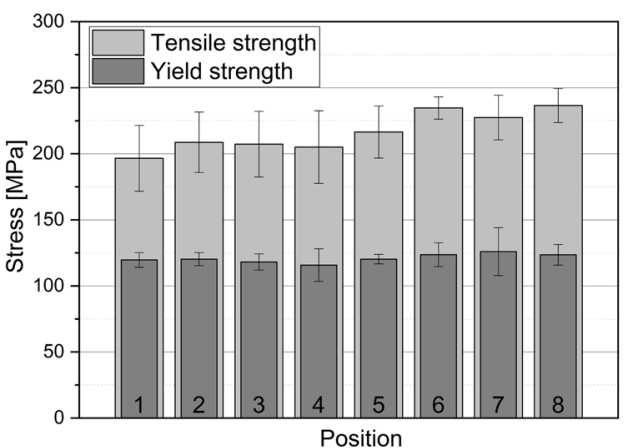

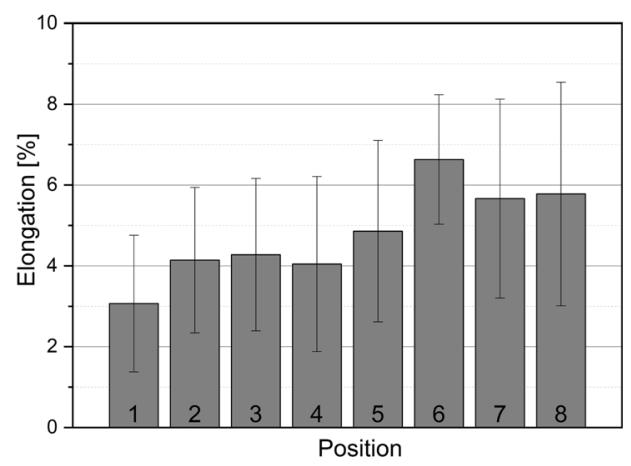


Fig. 6 General view of the fracture surface of the prematurely cracked tensile specimen of the alloy EN AC-AlSi9Mn, the area with the cold shut is clearly visible (left) and rendered 3D model of the pore analysis of a tensile specimen next to the venting

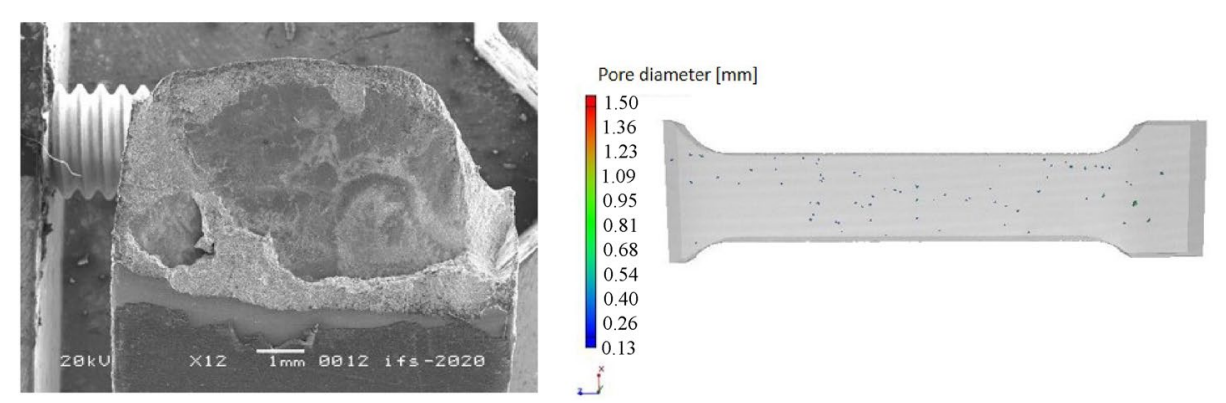

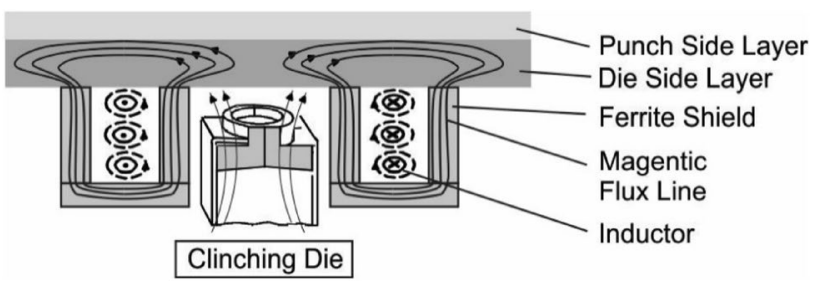

Fig. 7 Principle scheme of the shielding of the magnetic field lines

fracture surface and perpendicular to the load. This area is a cold shut in the material. The difference between the light, fissured and dark, smooth areas can be clearly seen. Figure 6 on the right shows a rendered 3D model of a tensile specimen from the side of the demonstrator component far from the sprue. The pore size is in the range of $0.13-0.80 \mathrm{~mm}$, and the number is about 70 pores. In general, the porosity is low, which supports the explanation of the low strength values due to cold shut.

\subsection{Inductive heating and process sequence}

In induction heating, eddy currents are induced in a metal workpiece by an alternating electromagnetic field and these are converted into heat by the remagnetization losses. Therefore, in induction heating, the heat is induced directly into the workpiece without any external influence. Thus, this process has a relatively high efficiency. In the scope of this research, the inductive heating was used for the clinching die and the joining materials (sheet metal and die casting). The ferrite shield was installed all around the inductor, except for the surface facing the joining components. In this way, the magnetic field is concentrated exclusively in the parts to be joined and a small proportion in the clinching die (Fig. 7). In previous studies it could be shown, that this heating method is the most suitable in comparison to heating plate and resistance heating [12].

\subsection{Dimensions of clinch elements}

The dimensions of clinch elements, which contribute to the form fit, are used to assess the joint strength and mechanical properties. According to DVS-3420-1, the parameters are summarized in Fig. 8 [13]. The overlap between the compressed material and the initial material is referred to as the interlock $\mathrm{f}$. With its clamping with the die-side sheet, this ensures the necessary joint strength under peel and head tensile stresses. If the interlock is pronounced, the form fit of the joint is enhanced, which leads to an increase in joint strength. The neck thickness $t_{n}$ is the thinnest section at the transition from the punch-side sheet to the clinch point. Since this parameter is mainly responsible for the joint strength under shear stress, the joint strength can be increased by increasing its thickness. For non-destructive testing of the clinch point, the bottom thickness $t_{b}$ can be taken as a measure [14].

\section{Results}

In the following chapters, the experimental results are shown. The focus is on the time-temperature curve, the surface analysis, the geometrical dimensions of the clinching point and the bonding strength of the joint.

\subsection{Time-Temperature curve}

Figure 9 shows the time-temperature curve when using a time-regulated approach. The curves shown are a mean value, each consisting of five measurements. For this test, a type $\mathrm{K}$ thermocouple was inserted into the die casting material via a $0.6 \mathrm{~mm}$ wide and $11 \mathrm{~mm}$ deep hole. The components to be joined were positioned at a distance of $3 \mathrm{~mm}$ from the inductor and fixed by means of a fixing device. It can be seen that the reference temperature is reached faster with increasing manipulated variable (power value). For example, the time for the inductor of the TOX clinching press at $50 \%(20 \mathrm{kHz})$ power value is $11.5 \mathrm{~s}$, while it is $5.5 \mathrm{~s}$ at $100 \%(40 \mathrm{kHz})$ power value. This is a time saving of $48 \%$. Comparable results are achieved with the inductor for the Eckold clinching press. Here, the time to reach the reference temperature at $20 \mathrm{kHz}$ is $6.9 \mathrm{~s}$ and $4.5 \mathrm{~s}$ at $40 \mathrm{kHz}$. This results in a time saving of $35 \%$. The different warm-up times at the same control variable are mainly due 
Fig. 8 Dimensions of clinch elements of a rigid die (up) and a flexible die (down) [13]
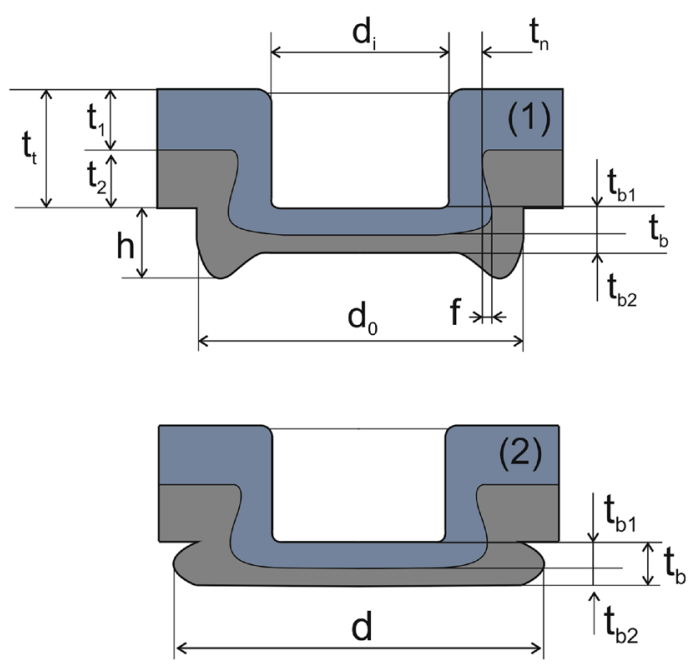

(1) Clinchpoint with rigid die

(2) Clinchpoint with flexible die

\begin{tabular}{|c|c|}
\hline Abbreviation & Designation \\
\hline$d$ & outer diameter \\
\hline$d_{O}$ & nominal outer diameter \\
\hline$d_{i}$ & inner diameter \\
\hline$f$ & interlock \\
\hline$h$ & button height \\
\hline$t_{b}$ & bottom thickness \\
\hline$t_{b 1}$ & $\begin{array}{l}\text { punch side bottom } \\
\text { thickness }\end{array}$ \\
\hline$t_{b 2}$ & die side bottom thickness \\
\hline$t_{n}$ & neck thickness \\
\hline$t_{t}$ & total thickness \\
\hline$t_{1}$ & $\begin{array}{c}\text { punch side layer thickness } \\
\text { (1) }\end{array}$ \\
\hline$t_{2}$ & die side layer thickness (2) \\
\hline
\end{tabular}

Time-temperature curve for the inductor of the TOX Clinching Press

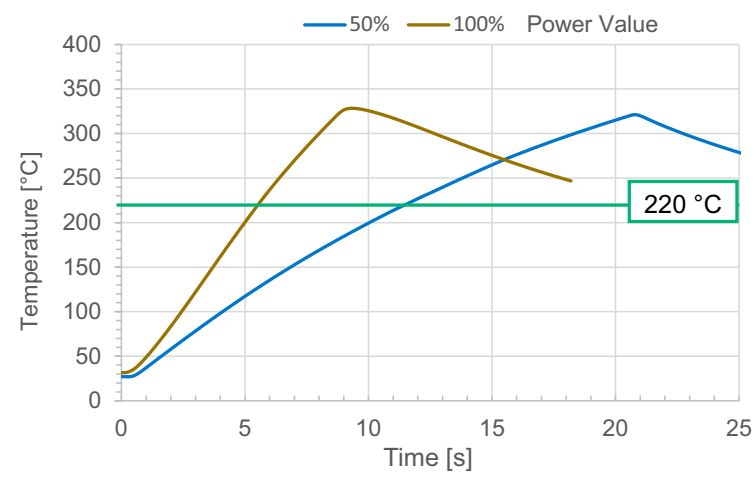

Time-temperature curve for the inductor of the Eckold Clinching Press

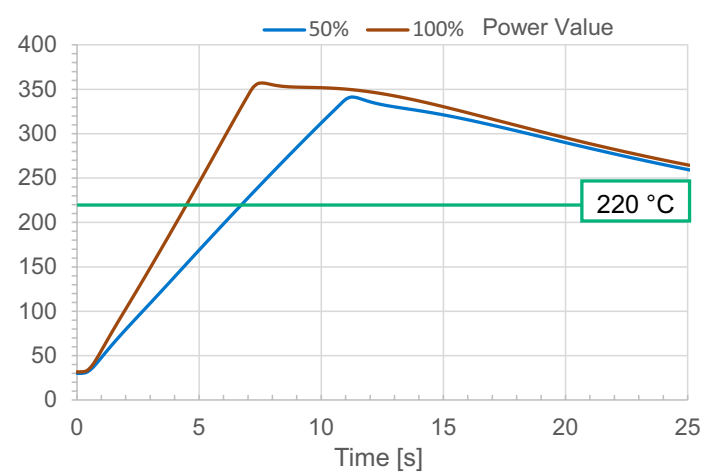

Fig. 9 Time-temperature curve for inductive heating with different manipulated variable (power value) for the inductor on the TOX clinching press (left) and the inductor on the Eckold clinching press (right)

to the different ring diameters of the inductors. A larger ring diameter leads to a larger magnetic field, which in turn can release more power.

\subsection{Surface analysis}

When examining the die-side surface of the clinch points, it was noticed that different heating temperatures are required depending on the die geometry. The BTM die system used in the Eckold clinching press was able to produce crack-free clinch points at temperatures of $260{ }^{\circ} \mathrm{C}$ in the die casting with a slightly higher heating time (5.6 s), while this was already reached at $220{ }^{\circ} \mathrm{C}$ with the TOX die system. The TOX die is a rigid die in which the heat is concentrated in the die body and this favors the clinching process (Fig. 10). According to Zhao [6], the reason for crack reduction is the dissolution of silicon agglomeration within the microstructure. The heating of the material, which increases the fracture elongation and causes the material to deteriorate in ductility, induces this [6].

There are two challenges with the flexible BTM die. One is the vulnerability of the springs to the high temperatures and the other is the insulating effect of the blades. The temperature causes the spring to lose a lot of elasticity, which limits the closing of the lamellae. The bulge is caused by the material becoming ductile and being discharged through the anvil. Furthermore, the lamellae act as an insulating shield for the core of the die, limiting the 


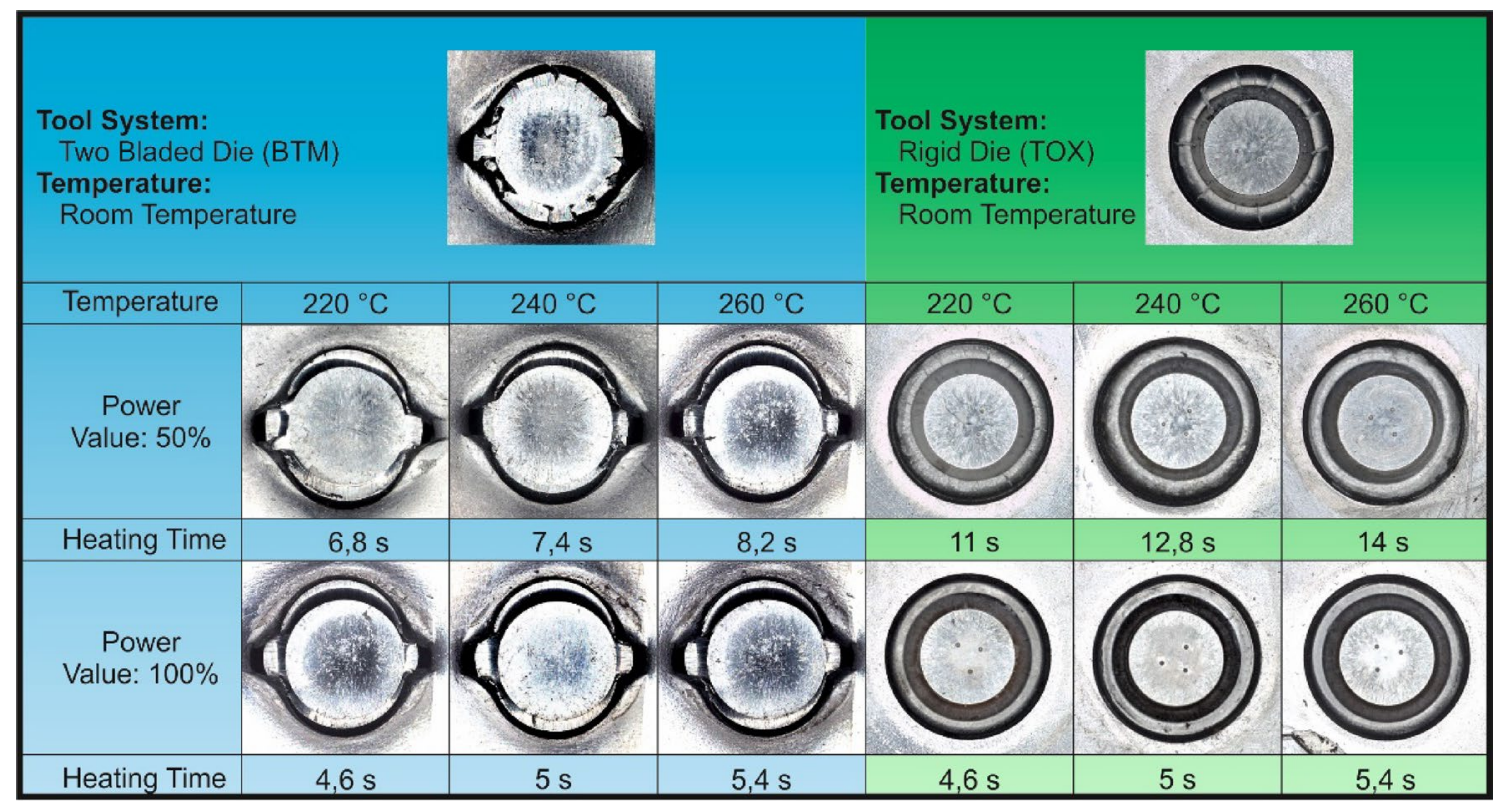

Fig. 10 Overview table of surface analysis of a moving BTM die (blue box) with a rigid die (green box) using a miniaturized inductor (colour figure online)

Fig. 11 Close-up surface analysis of a moving BTM die (blue box) with a rigid die (green box) using a miniaturized inductor (colour figure online)

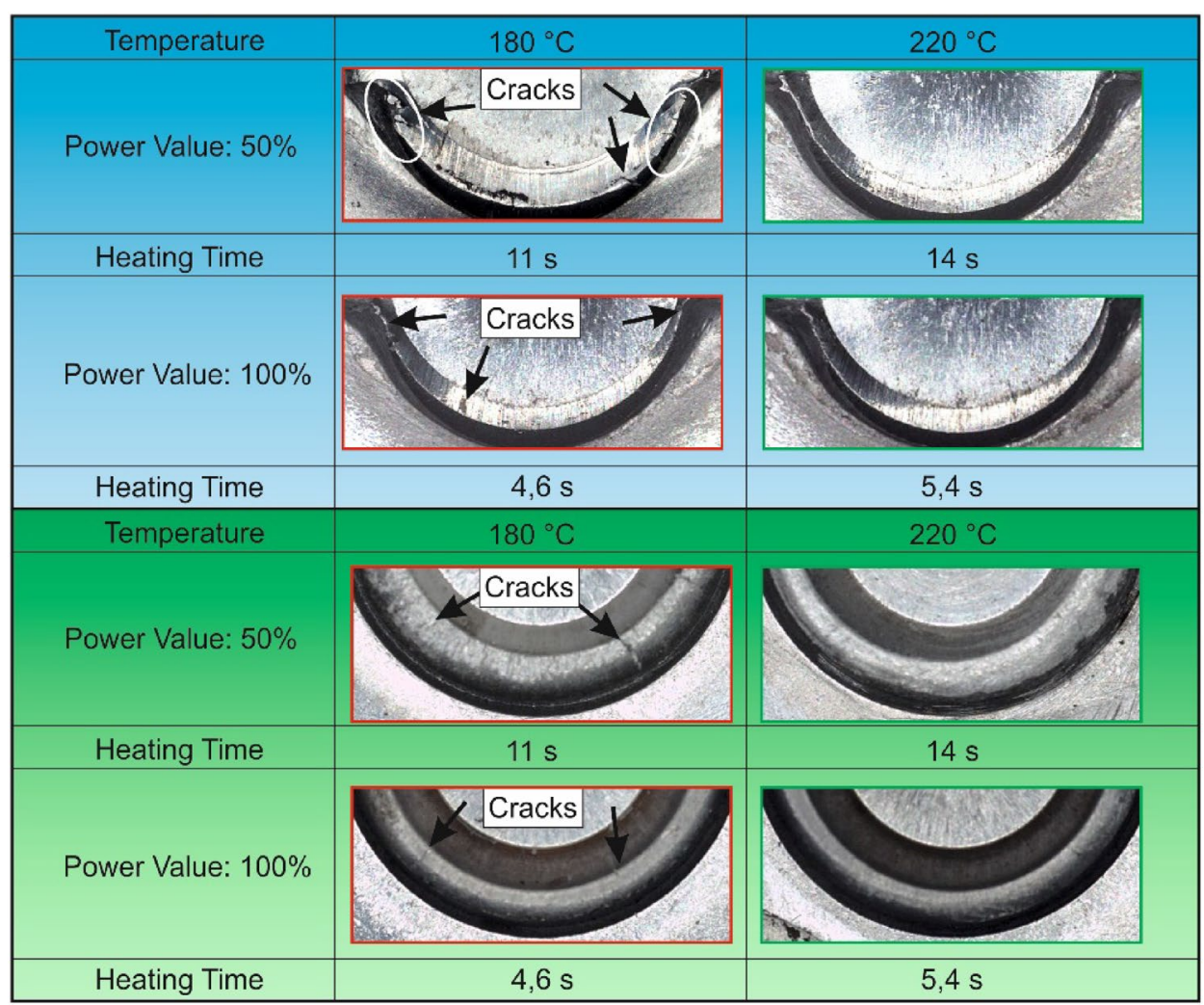


heating of the die and thus requiring higher temperatures (Fig. 11).

\subsection{Clinch point analysis}

With both tool systems, crack-free clinch points were produced in a time of less than $6 \mathrm{~s}$. From the micrographs, it can be seen that both tool systems result in similar effects on the dimension of the clinch elements. Although cracks are present on the surface of the die-cast components, they do not affect the joint strength when the clinch point is subjected to shear stress, since the cracks are only superficial and do not extend through the material. The neck thickness remains almost unchanged in both cases compared to the samples treated at room temperature. This indicates that the shear tensile strength remains the same, since it strongly depends on the extent of the neck thickness. The tempering process also produced more pronounced interlock $f$ than at room temperature with both tool systems. This can be explained by the better material flow behavior of the aluminum die casting, which results from the heating, see Table 1 . The results shown in Table 1 are mean values, each consisting of five measurements.

\subsection{Joint strength analysis}

The results of the clinch point analysis (Table 1) showed that neck thickness $t_{n}$ for both tool systems remains unchanged with inductive heating. As mentioned before, this indicates that the shear tensile load also remains unchanged. Therefore, this article does not take into account the shear tensile test. On the other hand, the interlock $\mathrm{f}$ is subject to a significant increase with up to $+47 \%$. Since the undercut is directly related to the head tensile strength, the head tensile strength has to be examined. The joint strength test was performed using a DYNA-MESS tensile testing machine type S100/ZD. The test was performed by means of the head tensile test in accordance with DVS 3480 . The test speed was $10 \mathrm{~mm} / \mathrm{min}$ for all specimens. The head tensile strength for both tooling systems were investigated and are shown in Fig. 12. Here, the direct comparison to clinched specimens at room temperature are presented. It can be noted that regardless of the tooling system, there have been increases in head tensile strengths. This amounts to an increase of $25 \%$ for the TOX tool system and an increase of $26 \%$ for the BTM tool system.

Table 1 Change of dimensions of the clinch elements from 20 to $220{ }^{\circ} \mathrm{C}$ of the specimen EN AW-5182 and EN AC-AlSi9Mn

\begin{tabular}{|c|c|c|c|c|c|c|c|c|}
\hline \multirow[t]{2}{*}{ Tool system } & \multicolumn{2}{|l|}{$\begin{array}{l}\mathrm{t}_{\mathrm{n}} \\
{[\mathrm{mm}]}\end{array}$} & \multicolumn{2}{|c|}{$\begin{array}{l}\mathrm{f} \\
{[\mathrm{mm}]}\end{array}$} & \multicolumn{2}{|c|}{$\begin{array}{l}\mathrm{t}_{\mathrm{b} 1} \\
{[\mathrm{~mm}]}\end{array}$} & \multicolumn{2}{|c|}{$\begin{array}{l}\mathrm{t}_{\mathrm{b} 2} \\
{[\mathrm{~mm}]}\end{array}$} \\
\hline & RT & Inductive heating & RT & Inductive heating & RT & Inductive heating & RT & Inductive heating \\
\hline TOX & 0.38 & $0.35(-9 \%)$ & 0.17 & $0.25(+47 \%)$ & 0.26 & $0.13(-50 \%)$ & 0.94 & $0.42(-55 \%)$ \\
\hline BTM & 0.25 & $0.25(0 \%)$ & 0.09 & $0.13(+30 \%)$ & 0.55 & $0.14(-80 \%)$ & 0.61 & $0.31(-50 \%)$ \\
\hline
\end{tabular}

Fig. 12 Head tensile strength of the clinching joints at room temperature and at $220^{\circ} \mathrm{C}$ for a rigid die (TOX) and a flexible die (BTM)

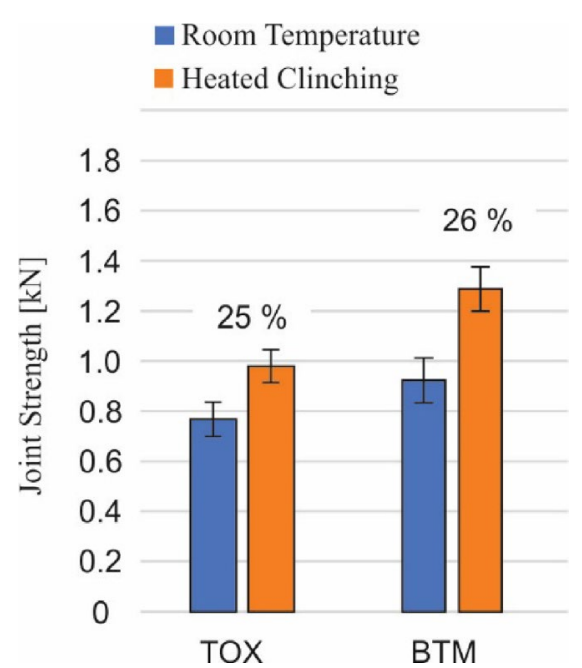

Head tensile strength

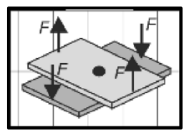

Punch side:

EN AW 5182 (1.5 mm)

Die side:

Sample Number:

Heating Time:

EN AC-A1Si9Mn (3 mm)

6

$5.4 \mathrm{~s}$

Power value: $\quad 100 \%(40 \mathrm{kHz})$ 


\section{Summary and outlook}

Two right-angled inductor concepts, each adapted for a specific clinching press, were developed and manufactured in order to produce crack-free clinching points when using aluminum die casting. The inductors were attached to the clinching presses using their existing drills. Clinching tests were carried out with the aim of determining the minimum time window required as a function of joining part thickness considered. The different diameters of the ring inductors result in the generation of different magnetic fields and different time-temperature curves. This was demonstrated by observing the time-temperature curves of the individual inductors. The larger diameter of the inductor in the Eckold clinching press can achieve higher heating rates. For example, at a power value of $50 \%$, the reference temperature of $220{ }^{\circ} \mathrm{C}$ was reached after $6.9 \mathrm{~s}$, while the inductor for the TOX clinching press needed $11.5 \mathrm{~s}$ to get to the reference temperature. At a manipulated variable of $100 \%$, the time could be reduced to $4.5 \mathrm{~s}$ when using the inductor for the Eckold press and to $5.5 \mathrm{~s}$ for the TOX press inductor.

When examining the die-side surface of the clinch points, it was determined that different heating temperatures are required depending on the die geometry. The BTM die system was able to produce crack-free clinch points at temperatures of $260^{\circ} \mathrm{C}$ in die casting, while this was already possible at $220^{\circ} \mathrm{C}$ for the rigid die system (TOX). The TOX die is a rigid die in which the heat is stored in concentrated form in the die body, thus favoring the clinching process. In the case of the flexible die, the blades lead to a strong heat loss. Here, the blades act as an insulating shield for the core of the die, which restricts heating and thus requires higher temperatures. With both die systems, the generation of crack-free clinch points was possible in a time of less than $6 \mathrm{~s}$. The micrographs showed that the neck thickness in both die systems remained almost unchanged compared to clinched specimens at room temperature. This indicates a constant shear tensile strength, since this is strongly dependent on the neck thickness. The tempering clinching process produced a more pronounced interlock in both die systems than at room temperature. This can be explained by the better material flow behavior of the aluminum die casting resulting from the heating. The investigation of the joint strength showed an increase of up to $26 \%$ was measured for the head tensile load (BTM-die), which can be attributed to the more pronounced interlock.

In further investigations, real die casting components from an automotive supplier will be examined by taking into account the presented results.

Acknowledgements The project Clinching of Aluminium Die Casting Ref.-No. AiF 20279N was financed and supervised by the European Research Association for Sheet Metal Working (EFB). In the scope of the program to promote Industrial Collective Research it was funded by the German Federation of Industrial Research Associations (AiF) with means of the Federal Ministry of Economic Affairs and Climate Action (BMWK) on the basis of a decision by the German Bundestag. Furthermore, the authors would like to thank the industrial partners in this research project.

Funding Open Access funding enabled and organized by Projekt DEAL.

Open Access This article is licensed under a Creative Commons Attribution 4.0 International License, which permits use, sharing, adaptation, distribution and reproduction in any medium or format, as long as you give appropriate credit to the original author(s) and the source, provide a link to the Creative Commons licence, and indicate if changes were made. The images or other third party material in this article are included in the article's Creative Commons licence, unless indicated otherwise in a credit line to the material. If material is not included in the article's Creative Commons licence and your intended use is not permitted by statutory regulation or exceeds the permitted use, you will need to obtain permission directly from the copyright holder. To view a copy of this licence, visit http://creativecommons.org/licenses/by/4.0/.

\section{References}

1. Hirsch $\mathbf{J}$ (2011) Aluminium in innovative light-weight car design. Mater Trans 52(5):818-824

2. Taub AL, Krajewski PE, Luo AA et al (2007) The evolution of technology for materials processing over the last 50 years: the automotive example. JOM 59(2):48-57

3. Audi MediaCenter (2021) https://www.audi-mediacenter.com/ de/hightech-trifft-handarbeitdie-produktion-des-audi-e-tron-gtin-den-boellinger-hoefen-13242/leidenschaft-fuer-qualitaet-undprogressivitaet-der-neue-audi-e-tron-gt-13243

4. Behrens B-A, Bouguecha A, Vucetic M, Hübner S, Yilkiran D, Jin Y, Peshekhodov I (2015) FEA-based optimisation of a clinching process with an open multiple-part die aimed at damage minimisation in CR240BH-AlSi10MnMg joints. Mater Sci Eng Chem $21: 1-7$

5. Zhao X, Meng D, Zhang J, Han Q (2020) The effect of heat treatment on die casting aluminum to apply self-pierce riveting. Int $\mathbf{J}$ Adv Manuf Technol 109:2409-2419

6. Zhao X (2019) Research on applying the self-pierce riveting (SPR) for die casting aluminum alloys. A Dissertation submitted to the Faculty of Purdue University

7. Böllhoff (2021) Joining of aluminium cast with new ring groove die, Homepage. https://www.boellhoff.com/de-en/news/news/ 2017/rivset-ring-groove-die.php

8. Jäckel M, Coppieters S, Hofmann M, Vandermeiren N, Landgrebe D, Debruyne D, Wallmersberger T, Faes K (2017) Mechanical joining of materials with limited ductility: analysis of processinduced defects. In: Proceedings of the 20th international ESAFORM conference on material forming, AIP conference proceedings, vol 1896, pp 110009-1-110009-6

9. Hovanski Y, Upadyay P, Kleinbaum S, Carlson B, Boettcher E, Ruokolainen R (2017) Enabling dissimilar material joining using friction stir scribe. JOM 69(6):1060-1064

10. Ang HQ (2021) An overview of self-piercing riveting process with focus on joint failures, corrosion issues and optimisation techniques. Chin J Mech Eng 34:2. https://doi.org/10.1186/ s10033-020-00526-3 
11. Wang JW, Liu ZX, Shang Y et al (2011) Self-piercing riveting of wrought magnesium AZ31 sheets. J Manuf Sci Eng 133(3):031009

12. Yarcu S, Huebner S, Yilkiran D, Brunotte K, Behrens B-A, Schuchardt T, Mueller S, Dilger K (2021) Clinching of heated aluminium die cast. In: Journal: proceedings of the 11th congress of the German Academic Association for Production Technology

13. Merkblatt DVS/EFB 3420: Clinchen-Überblick / Clinching - basics (2018) DVS-Deutscher Verband für Schweißen und Verwandte Verfahren e.V., EFB-Europäische Forschungsgesellschaft für Blechverarbeitung e.V
14. Varis J (2006) Ensuring the integrity in clinching process. J Mater Process Technol 174:277-285

Publisher's Note Springer Nature remains neutral with regard to jurisdictional claims in published maps and institutional affiliations. 